\title{
THE EGYPTIAN EXPERIMENT OF THE NATIONAL YOUTH HOUSING IN NEW ASSIUT CITY "BETWEEN NEEDS AND PROSPECTS"
}

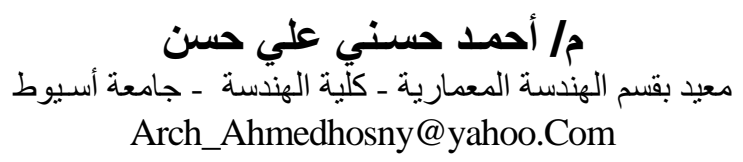

(Received December12, 2009 Accepted October 23, 2011)

A FAO*1 report indicated that young people are increasing worldwide. Statistics indicate that the percentage of youth (18-35) is about $33 \%$ of the total population in 2006. so, the U-20 age category represent $70 \%$ of the population, a unique structure of Egypt. The Egyptian society, now and in the future, is a youth society. A recent official statistical report (2007) revealed that the number of never married young men and women, though 35 in age, reached about 12 millions. Hence, came the cause of attention to solving the lowincome youth housing problem. Distinguishing between giving tranquilizers and providing radical solutions for housing problems; is vital for solving them. It can be said that there is a causative relationship between (the low productivity of low-income youth) and (the obstacles to solving the housing problem). So, it takes an integrated work system, and nontraditional meanswhether by the state, the individuals, or the NGOs *2-to solve this problem.

This paper attempted to study the gap between supply and demand, and the role of the government for creating some balance by turning towards new cities: starting from youth housing projects and ending by the projects "Build your house" and "Build your apartment"- a new project under study. But, were these cities an attraction or an expeller for youth and low-income? Is it possible to take new decisions to measure the efficiency of these projects after handing residential units to users (post-occupancy evaluation)? How far are users satisfied with these units? How can these units be preserved and maintained? This is done by evaluating these projects, and studying their cons and pros to make use of the evaluation results in similar future projects.

Despite being a third generation new city; New Assiut City suffers, like any other new city, from youth abandonment. Though there were official attempts to relieve the burden from youth's shoulders; still youth abandon New Assiut City, with a number of residents not exceeding 37\%, 15 thousands in 2009*3, of the total targeted number estimated by 40 thousands in 2010, according to the first planning of the city.

Thus, a gap emerged between the theoretical view of the government and the designer, in one side, and the facts of users' needs. A frame was reached, trying to integrate the different views of accomplishing users' needs and their concept of a suitable house. As for post-occupancy, we are trying to study

* FAO: Food and Agriculture Organization, United Nations.

NGO: Non- Government Organization.

Source: a field survey conducted by the researcher in April-May, 2009. 
residence (some models from the national youth housing project in New Assiut City) to learn how convenient it is for users and try to avoid defects in such future projects, in an attempt to achieve the most convenient residence for occupants.

\section{التجربة المصرية للإسكان القومي للثباب بمدينة أسيوط الجديدة " بالإمكاتئ "}

ملخص البحث:

يثنير تقرير لمنظمة الأغذية و الزر اعة أن هناك تز ايدا في أعداد الثباب على مستوى العالم؛ ولعل المؤشرات

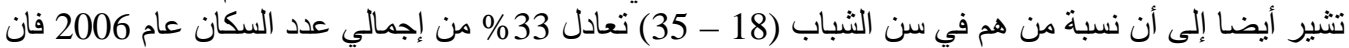

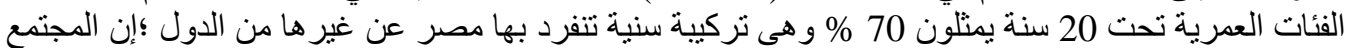

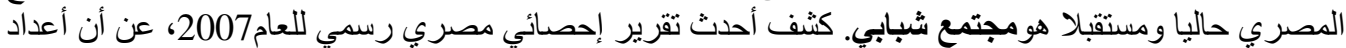

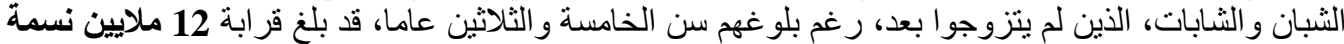

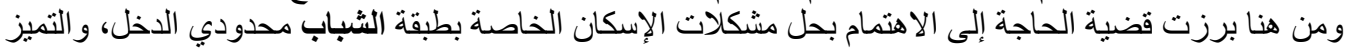

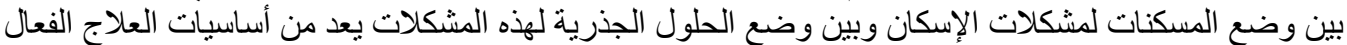

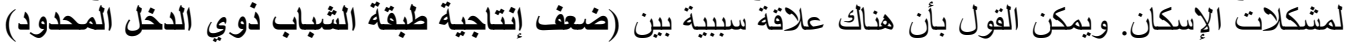

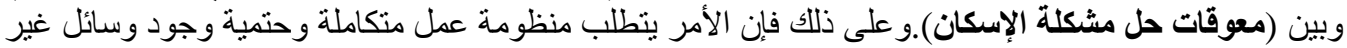

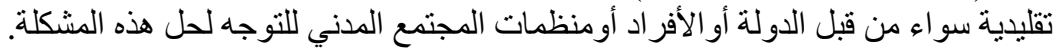

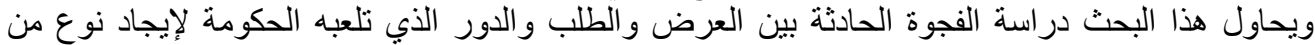

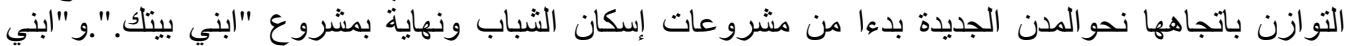

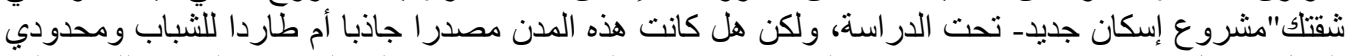

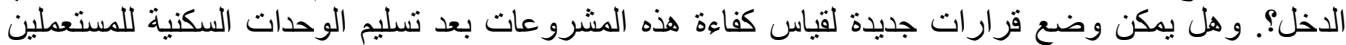

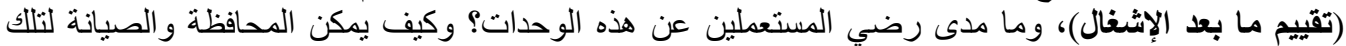

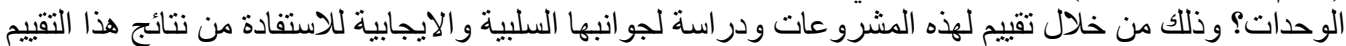

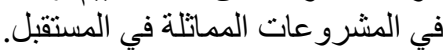
و وعلى الرغم من أن مدينة أسيوط الجديدة تعد من مدن الجيل الثالث للمدن الجديدة بمصر إلا إنها تعاني -

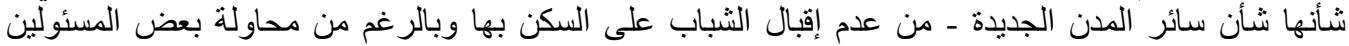

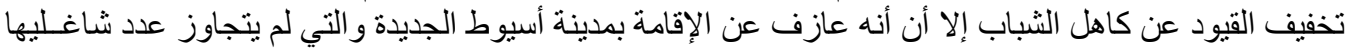

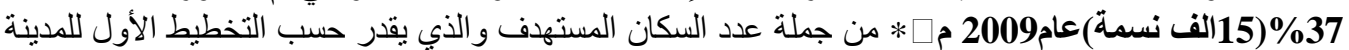
(40)

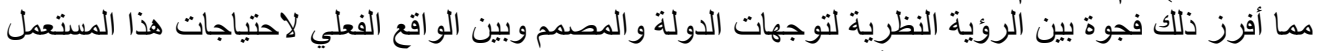

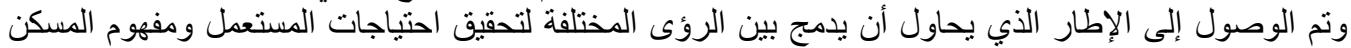

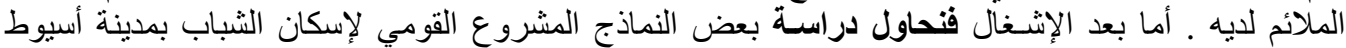

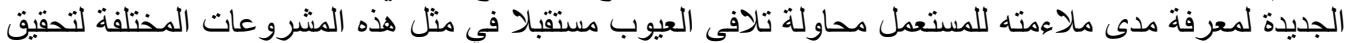

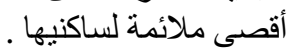

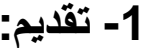

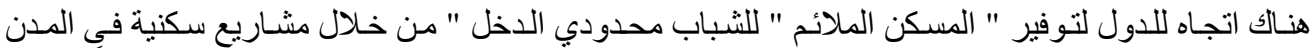

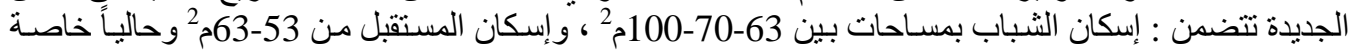

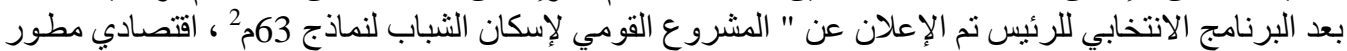

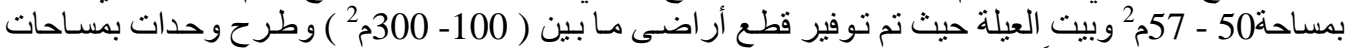

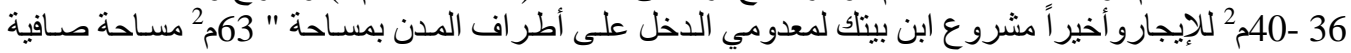




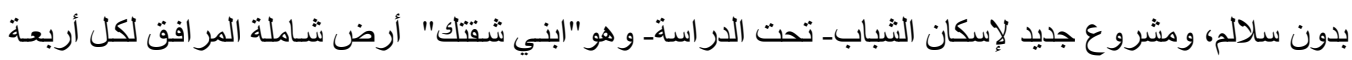

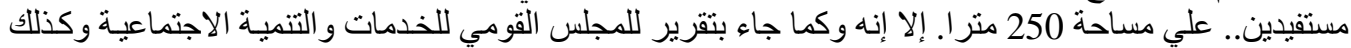

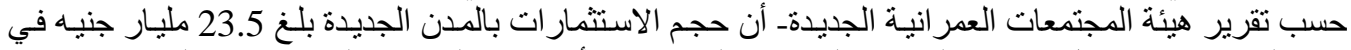

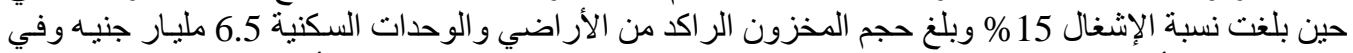

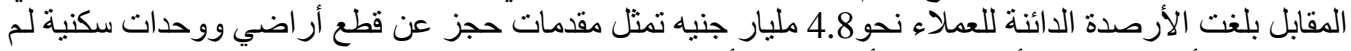

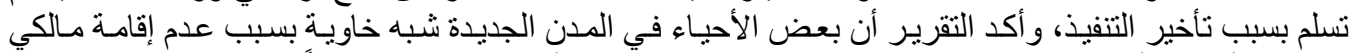

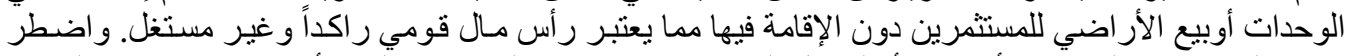

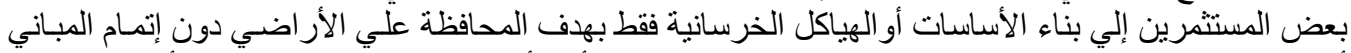

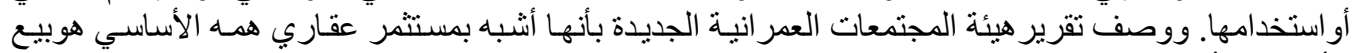

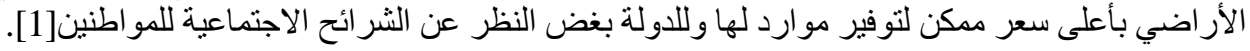

\section{1-1-1 خلفية عامة لمشكلة إسكان الثباب (محدودي الاخل) في مصر:}

في قضية إسكان الثباب ومحدودي الاخل هناك ثنلاث حقائق يكاد بسلم بها الجميع هي:

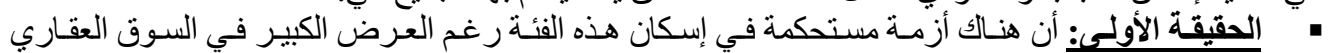

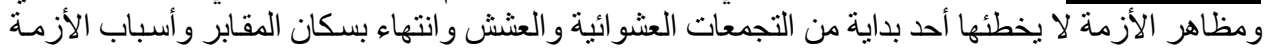

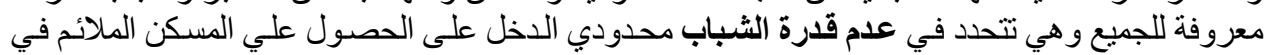
حدود القدر ات المتاحئة.

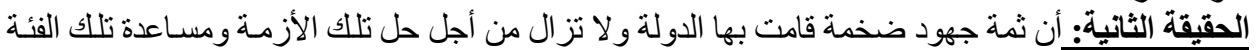

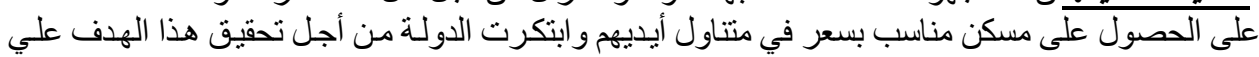

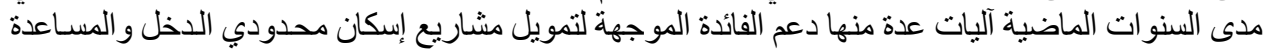

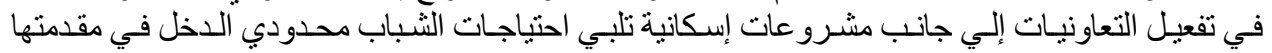

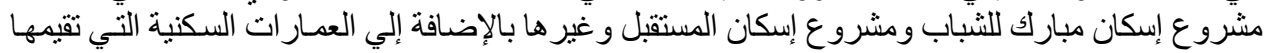

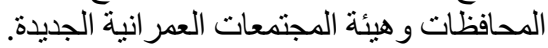

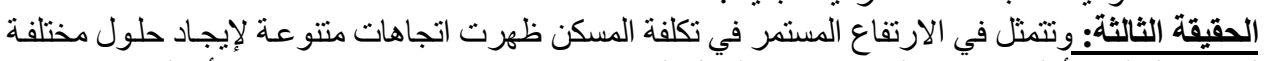

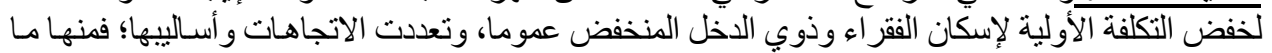

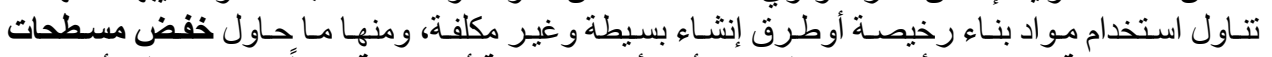

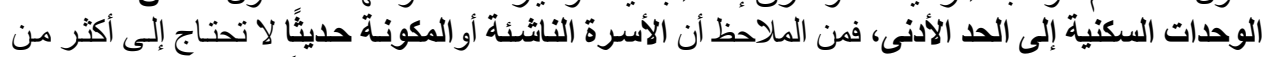

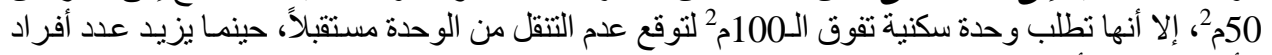

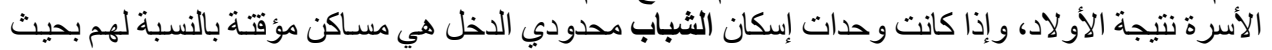

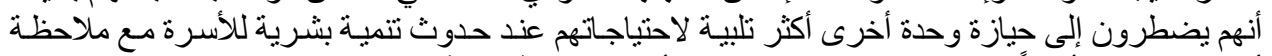

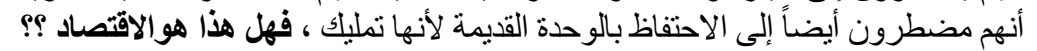

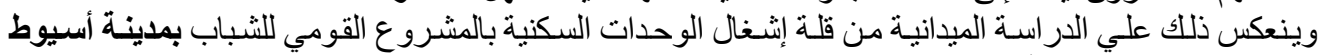

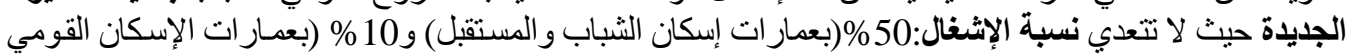

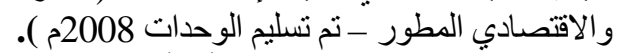

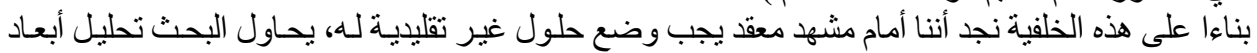

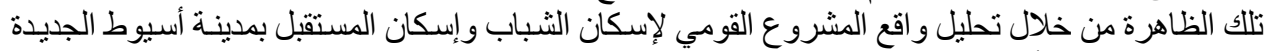
وذللك للتعرف على أسباب عزوف الثباب عن الإقامة بالمدينة.

\section{2-1 الهُف من الدراسة:}

إن هذه الدر اسة تهدف بالمقام الأول إلي تحليل و اقع المشروع القومي لإسكان الثباب و إسكان المستقبل بمـدينة

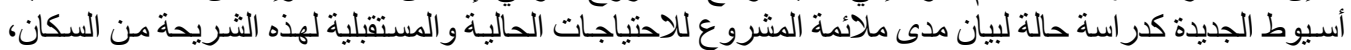
و إلقاء الضوء على " الاحتياجات " التي يحاول مدئ ماندة الساكن تحقيقها. 
3-1-1

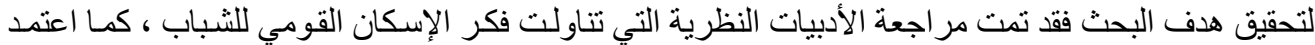

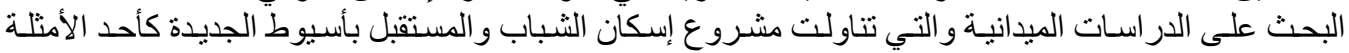

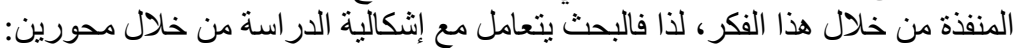

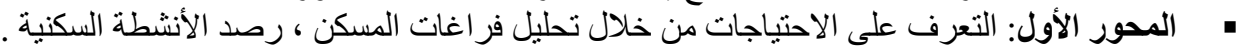

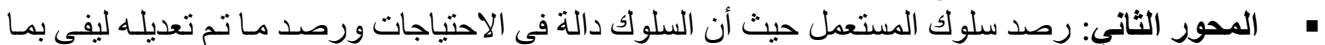

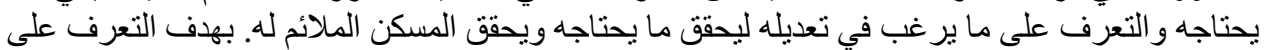
أُهم ايجابيات وسلبيات التجربة.

\section{2- دراسة تحليله لمشروع مبارك القومي لإسكان الشباب و إسكان المستقبل والاقتصادي}

\section{المطور والإسكان القومي بأسيوط الجديدة :}

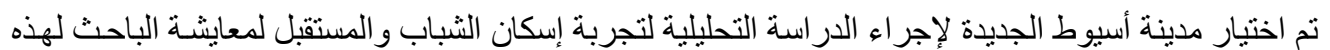

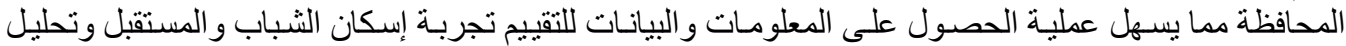

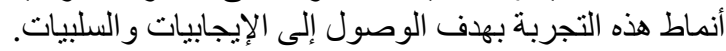

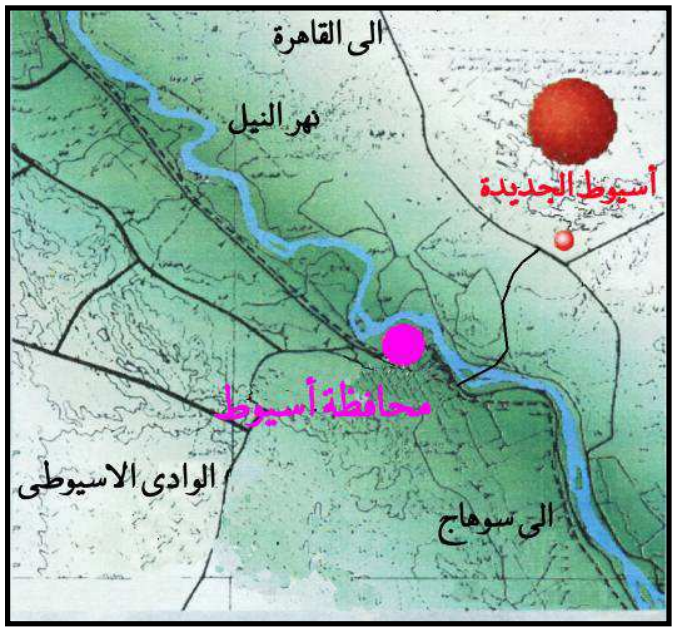

www. Urban - comm..gov: المصدر

شكل (1): موقع مدينة أسيوط الجديدة [6]

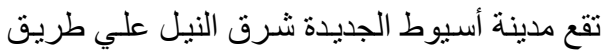

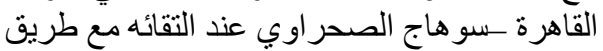

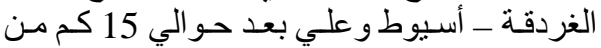

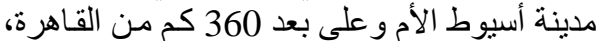

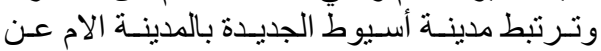
طريق :1- محور قناطر أسيوط. 2- محور الكوبري العلوي علي النيل ـ كوبري الني المساحة الكلية للمدينة (الكردون) 33.50 الوسطي ألف فدان، ومساحة الكتلة العمر انية 2950 فدان

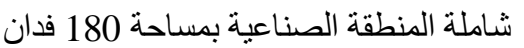
ـ من المقرر ان تستو عب المدينة 100 ألف فئدة نسمة في سنة الهذف 2017 م . - بلغ إجمالي استثمار ات المدينة 482 مليون جنيه حتي 2008/4/30 - يبلغ عدد سكان المدينة 12000 نسمة مقيمين بالمدينة وذلك بخلاف حو الي 3000 نسمة من العن العمالة و المنرددين علي المدينة يوميا. [5] 

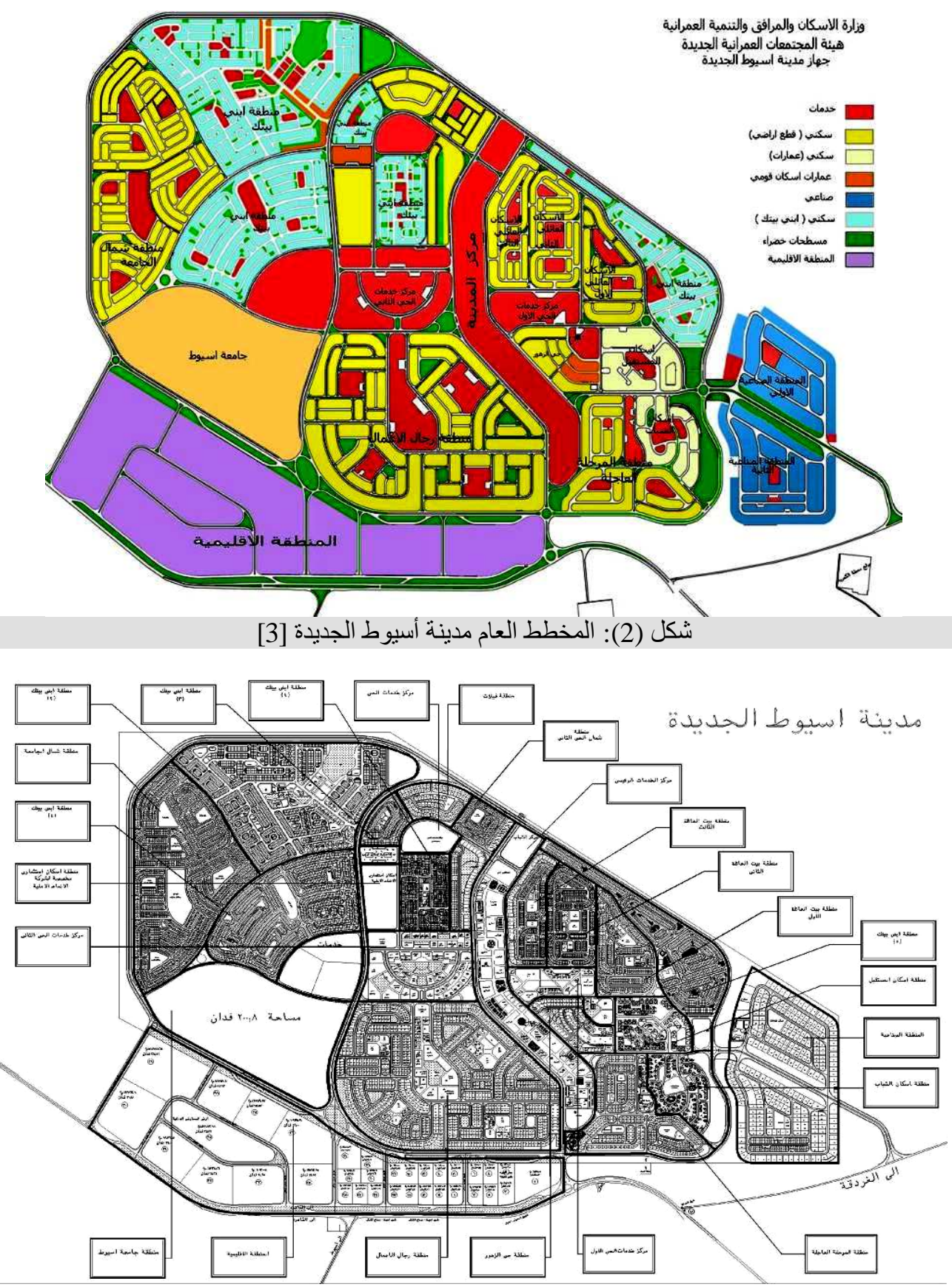

شكل (3): مكونـات مدينـة أسيوط الجديدة [3]

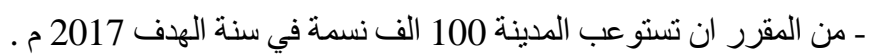

ـ ي يلغ عدد سكان المدينة 12000 نسمة مقيمين بالمدينة في يناير 2009م وإن وإجمالي الوحدات السكنية 3722 وحدة

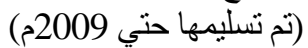

وذللك بخلاف حو الي 3000 نسمة من العمالة و المترددين علي المدينة يوميا. [3] 
جدول (1) : توزيع الاستمارات حسب نسبة الإشغال للوحدات السكنية بمدينة أسيوط الجديدة- اجمالي عدد الوحدات السكنية بالمشروع 3722وحدة سكنية

\begin{tabular}{|c|c|c|c|c|c|}
\hline \multicolumn{3}{|c|}{ عدد الوحدات السكنية } & المنطقة & الاستمارات & 药 \\
\hline \multicolumn{3}{|c|}{1906 (سابق) - - 1543 (حالي) وحدة } & إسكــان الثبـــاب & 60 & \\
\hline \multicolumn{3}{|c|}{ ا 1024 وحدة } & إسكان المستقبل & 30 & \\
\hline \multicolumn{3}{|c|}{ 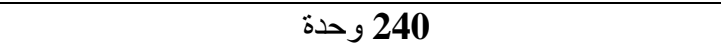 } & إسكان اقتصادي مطور & 20 & $=$ \\
\hline \multicolumn{3}{|c|}{ 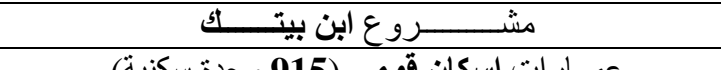 } & \multirow[b]{3}{*}{ إســــكان قومــــــي } & \multirow[b]{3}{*}{10} & 5 \\
\hline 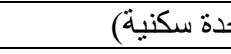 & 15) ان قومي & عمـار ات & & & \\
\hline صن ميانة ورفع كفاءة & وحدة جاري 300 & 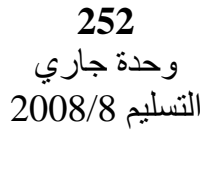 & & & $\frac{5}{5}$ \\
\hline
\end{tabular}

ـ ـ من الدراسة الاستطلاعية نجد أن نسبة الإشغال :

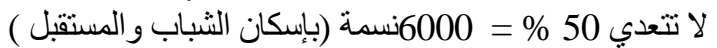
لا تتعدي 10 \% = 120نسمة (بالاسكان القومي و الاقتصادي المطور ) تم تسليم الوحدات 2008م .

الهدف من تطبيق الاستبيان على عينة المستعملين : - - قياس الحالة التعليمية و العو امل المتغيرة المختلفة المؤثرة على المستعطل واحتباجاته .

$$
\text { - }
$$

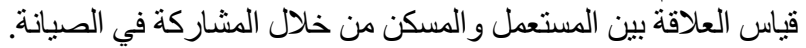

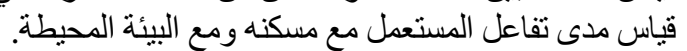

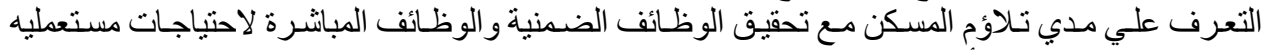

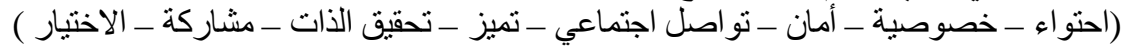

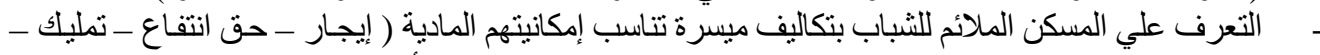

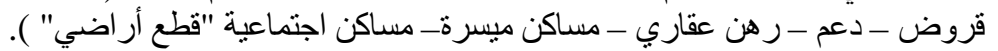
تنتاول الدراسة التحليلية استقر اء الرسومات و المساقط الأفقية و الو اجهات لبعض النماذج السكنية ذات المسطحات

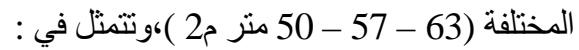
- - موذج (بندق - قمر الدين ) بإسكان الثباب و المستقبل، نماذج ( 4 - 8 وحدات / دور ) مشروع إسكان

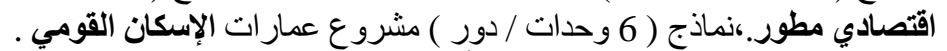

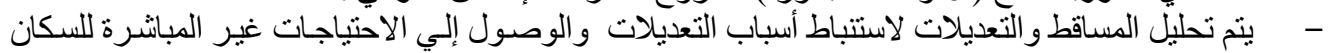

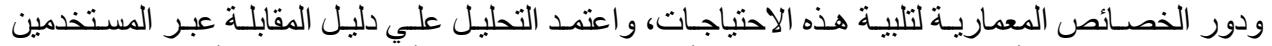

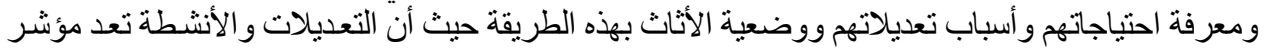

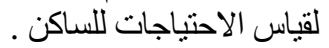



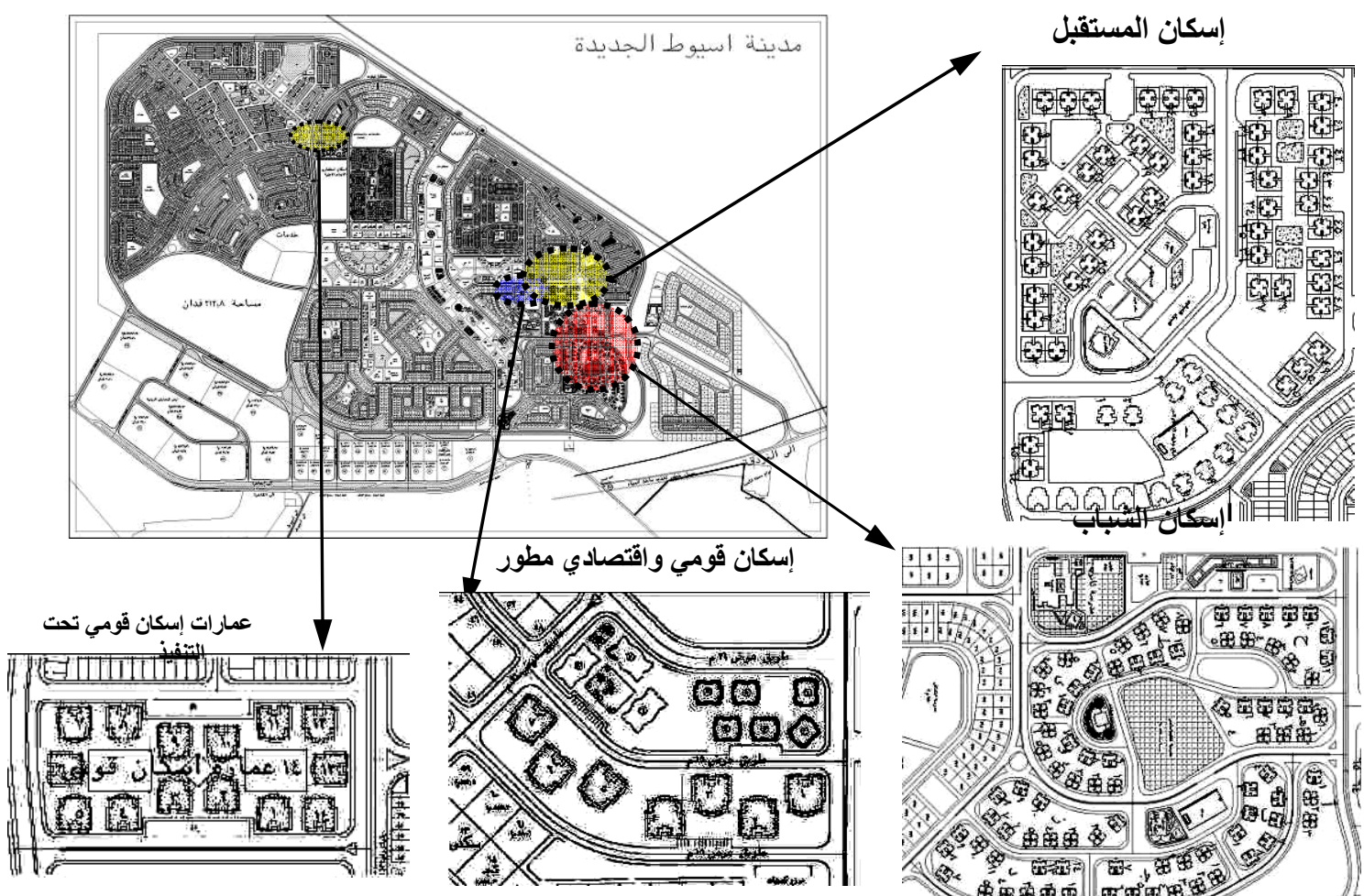

$$
\begin{aligned}
& \text { شكل (4): توزيع أماكن نماذج الإسكان المختلفة بمدينـة أسـيوط الجديدة }
\end{aligned}
$$

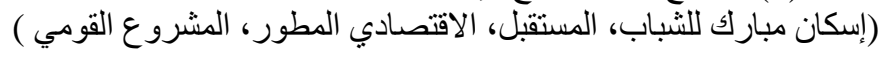$$
\text { 2-2 تحليل مجمع لنماذج المشروع القومي لإسكان الشباب بمدينة أسيوط الجديدة: }
$$$$
\text { (جميع النماذج تنكون من غرفتين وصالة وحمام ومطبخ ) }
$$

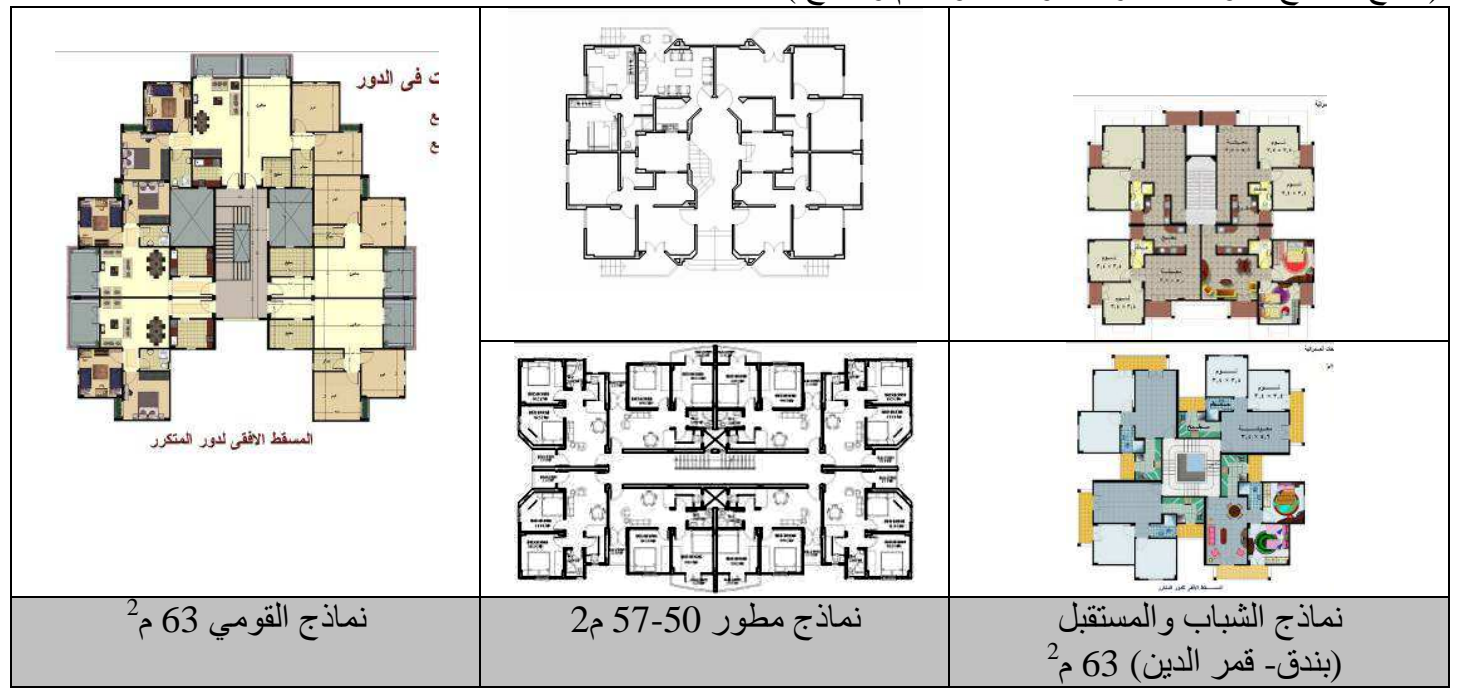

شكل (5): تحليل مجمع لنماذج المشروع القومي لإسكان الثباب بمدينة أسيوط الجديدة

$$
\text { على مستوى الفراغات : }
$$


مساحات الفراغات لا تفي بأداء الأنشطة داخلها في حالة وجود اكثرمن طفلين وقات وقد تختلف مسـاحة الفر اغات

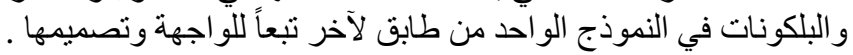

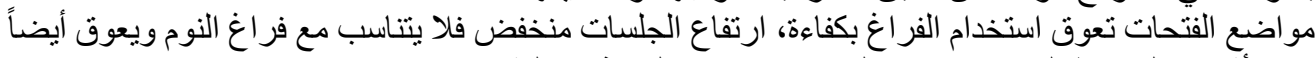

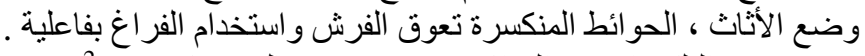

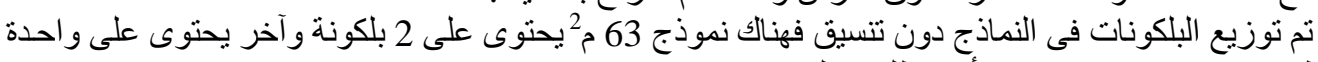

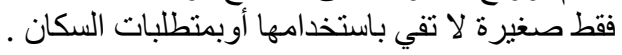

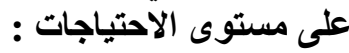
لا تتوفر الخصوص ملية بسبب قلّة ارتفاع جلسات الفتحات ، تلاصق أبو اب المداخل و البلكونات ، استخدام المطبخ

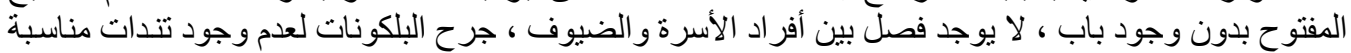

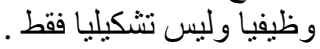
لا يتو افر الأمان خاصة في الدور الأرضي وضي ولا يوجد بو ابـات للعمار ات ، لا تتو افر علاقات اجتماعيـة وتكوين

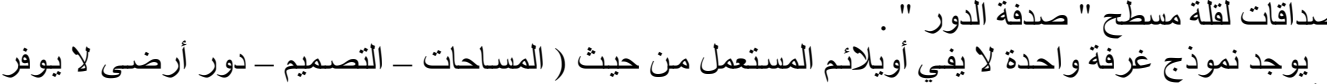

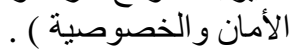

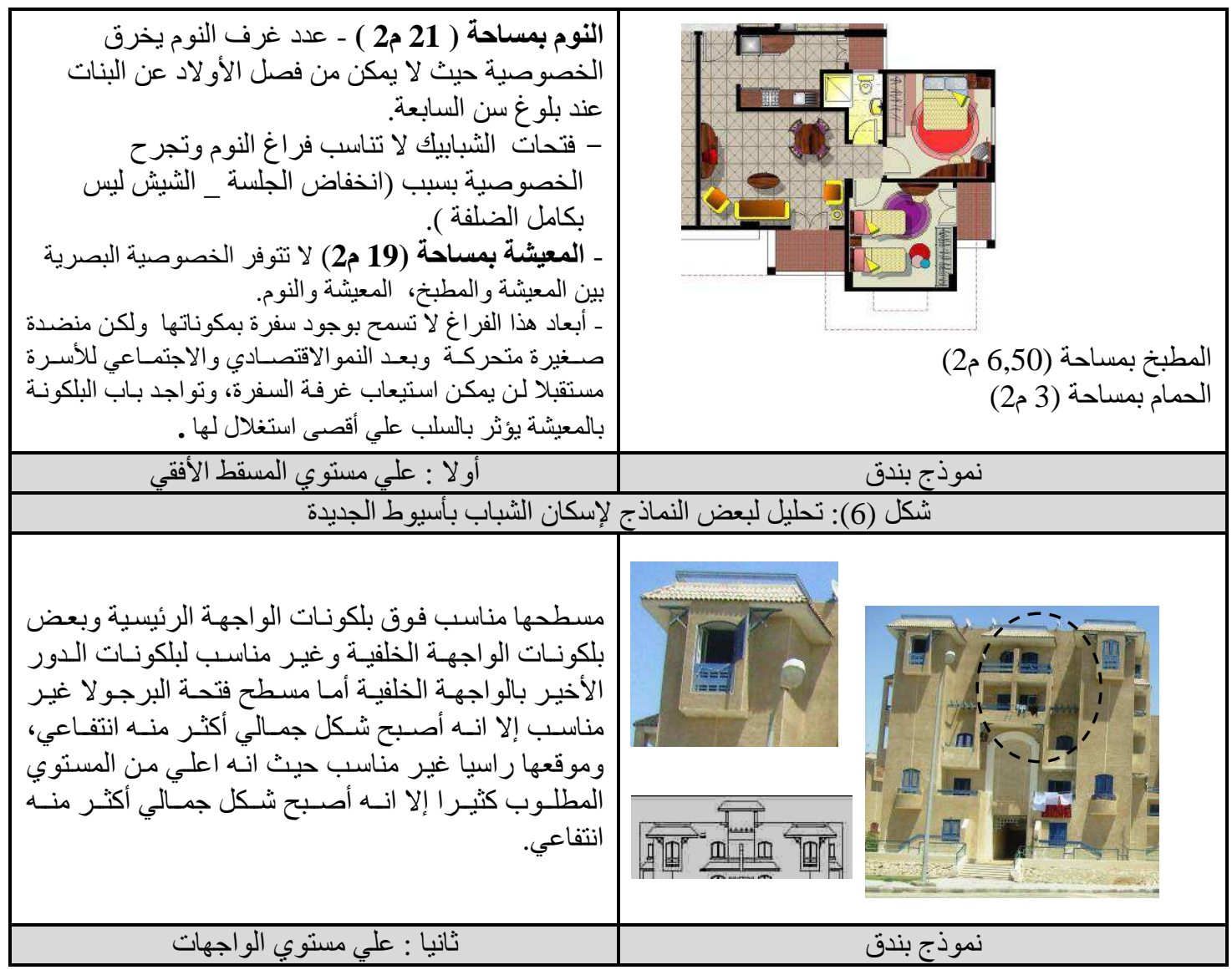




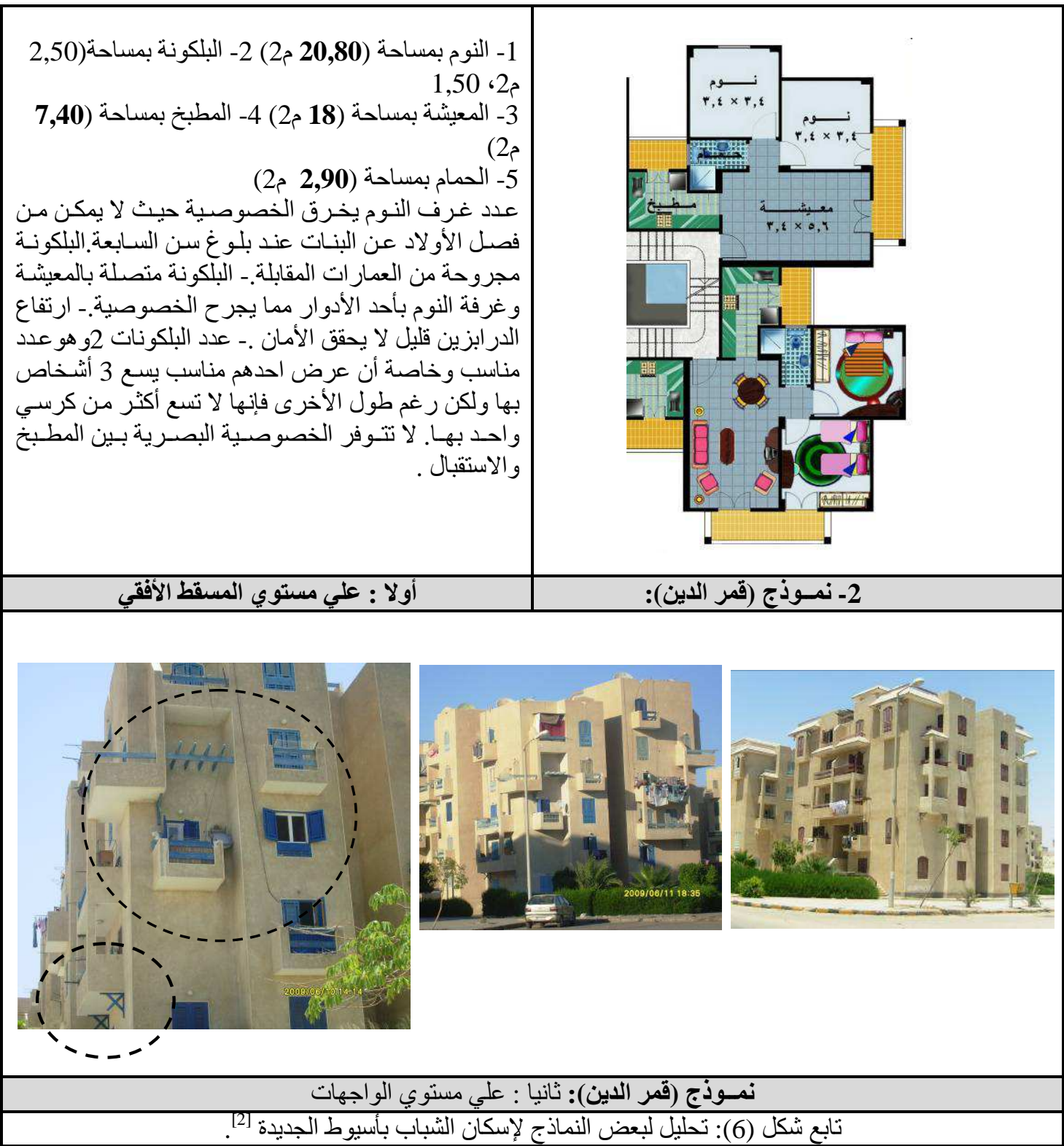

3-2 توثيق فرش وتعليلات المستعمل علي بعض النماذج :

يتم توثيق ورصد بعض النماذج المختارة بعد الإشغال وتوقيع الإضافات و التعديل وتوقيع الأنشطة السكنية داخل

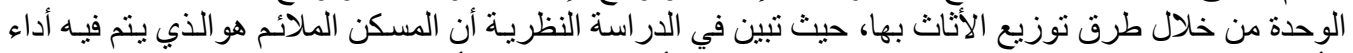

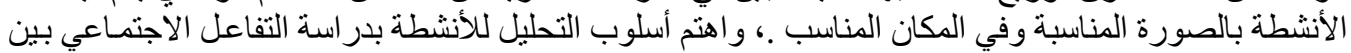

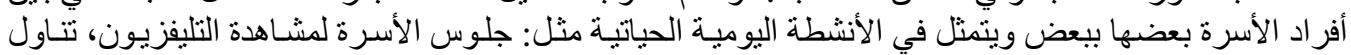

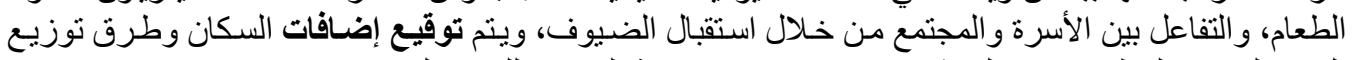
الفرش لتحقيق الوظائف غير المباشرة والاحتئياجات الإنسانية المتغيرة للمستعمل. 
1-3-2 توثيق الفرش علي بعض العينات بنموذج قمر الدين:
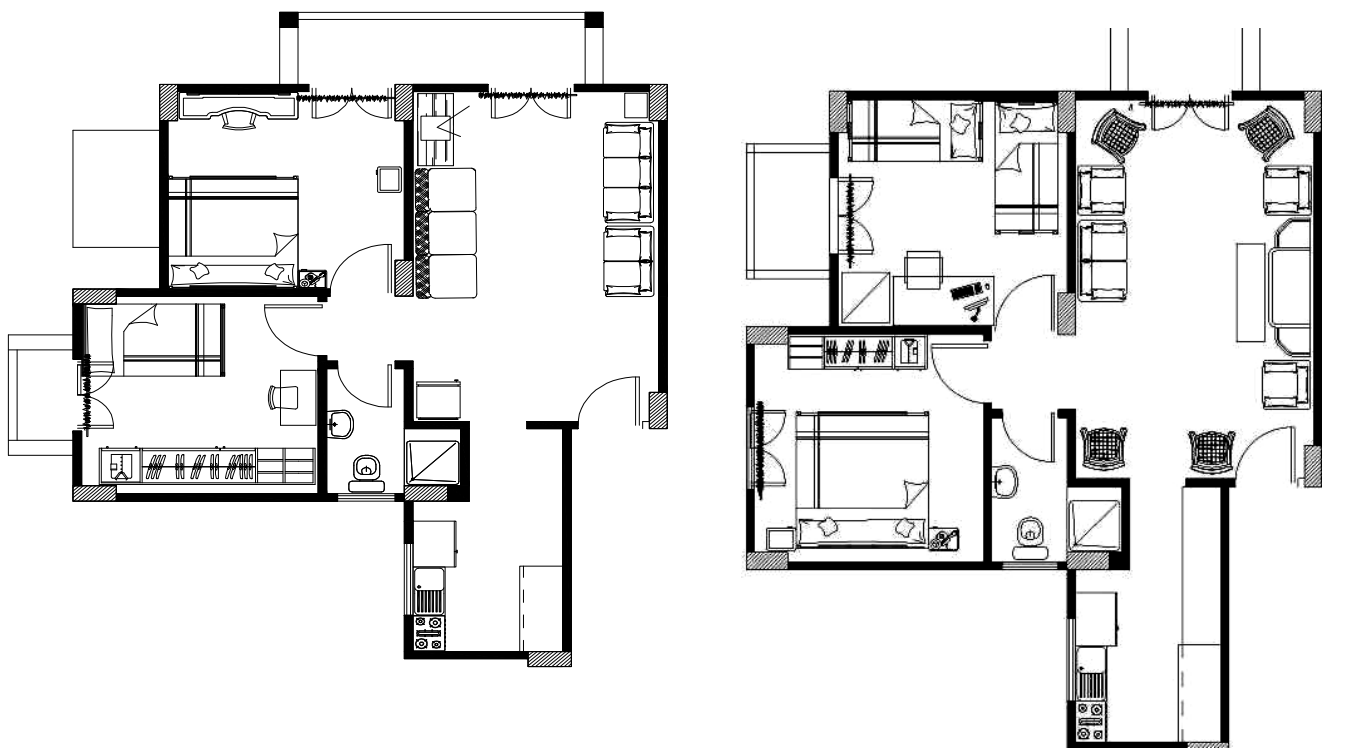

مسقط أفقي لعينة(2)

مسقط أفقي لعينة(1)

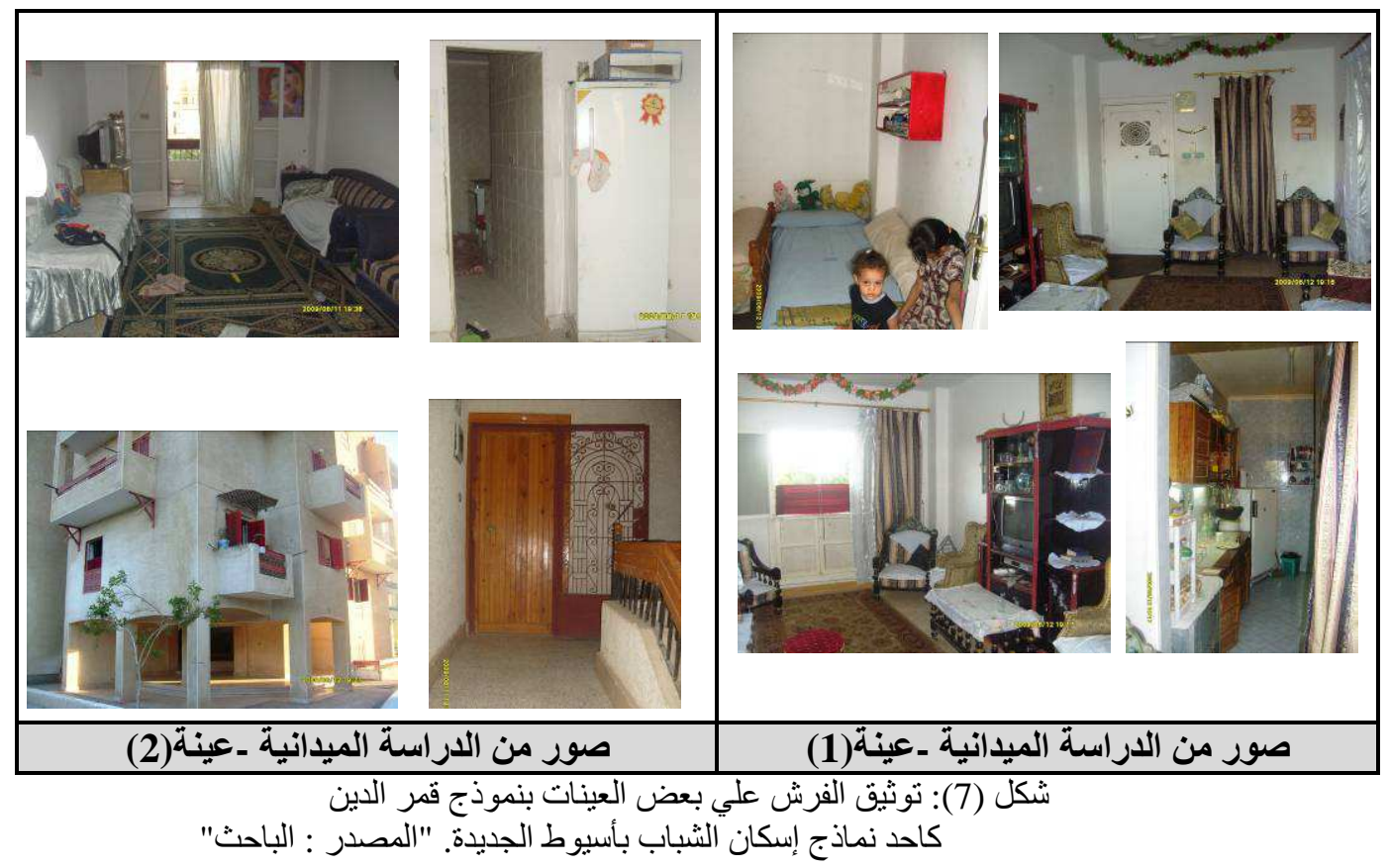


لصغر المساحة تم وضع 2-3-2 توثيق الفرش علي بعض العينات بنموذج بندق:

سريرين فقط في غرفة الأطفال

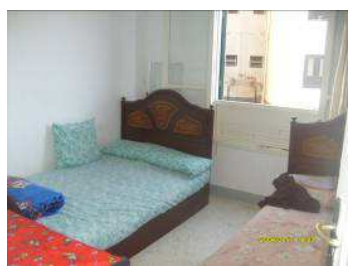
تم وضع الغسالة بغرفة نوم الطفلة لصغر مساحة الحمام

المساحة صغيرة جدا لدرجة استقطاع جزء من المطبخ لإضافة بانيوقدم
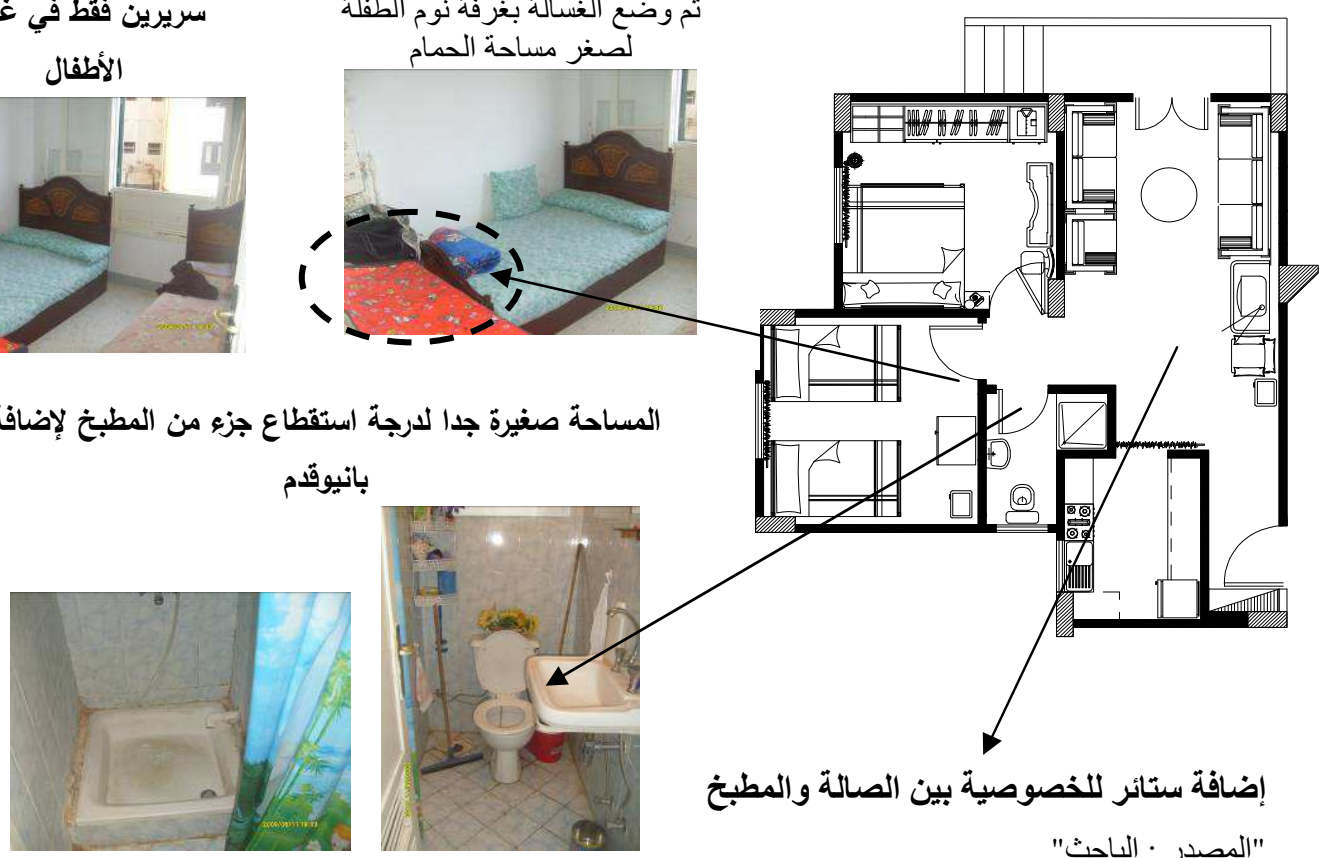

إضافة ستائر للخصوصية بين الصالة والمطبخ "المصدر : الباحث" 3-3-2 توثيق الفرش علي بعض العينات بنموذج اقتصادي مطور(4وحدات / دور):

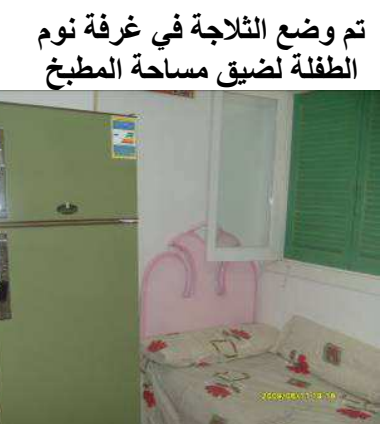

تم وضع الغسالة خارج الحمام لصغز مساحته الغ اله
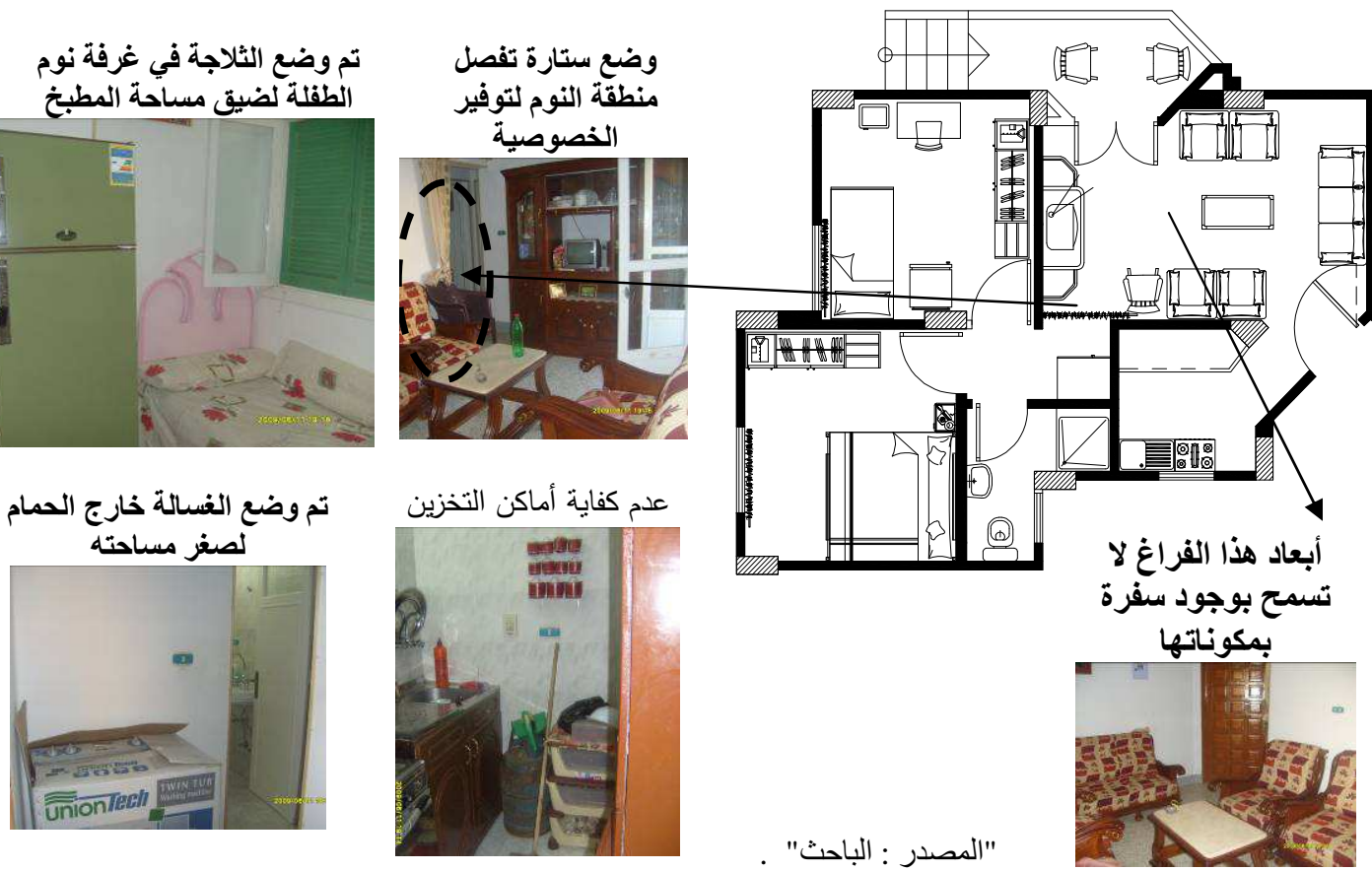
4-3-2 تابع توثيق تعليلات المستعمل علي بعض النماذج (في الواجهات):

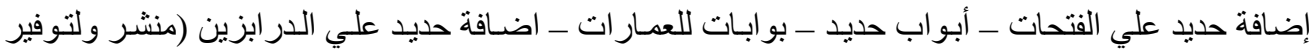

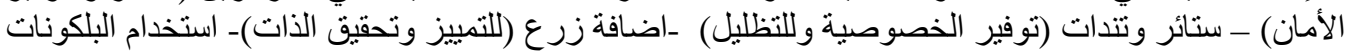
اللتخزين .
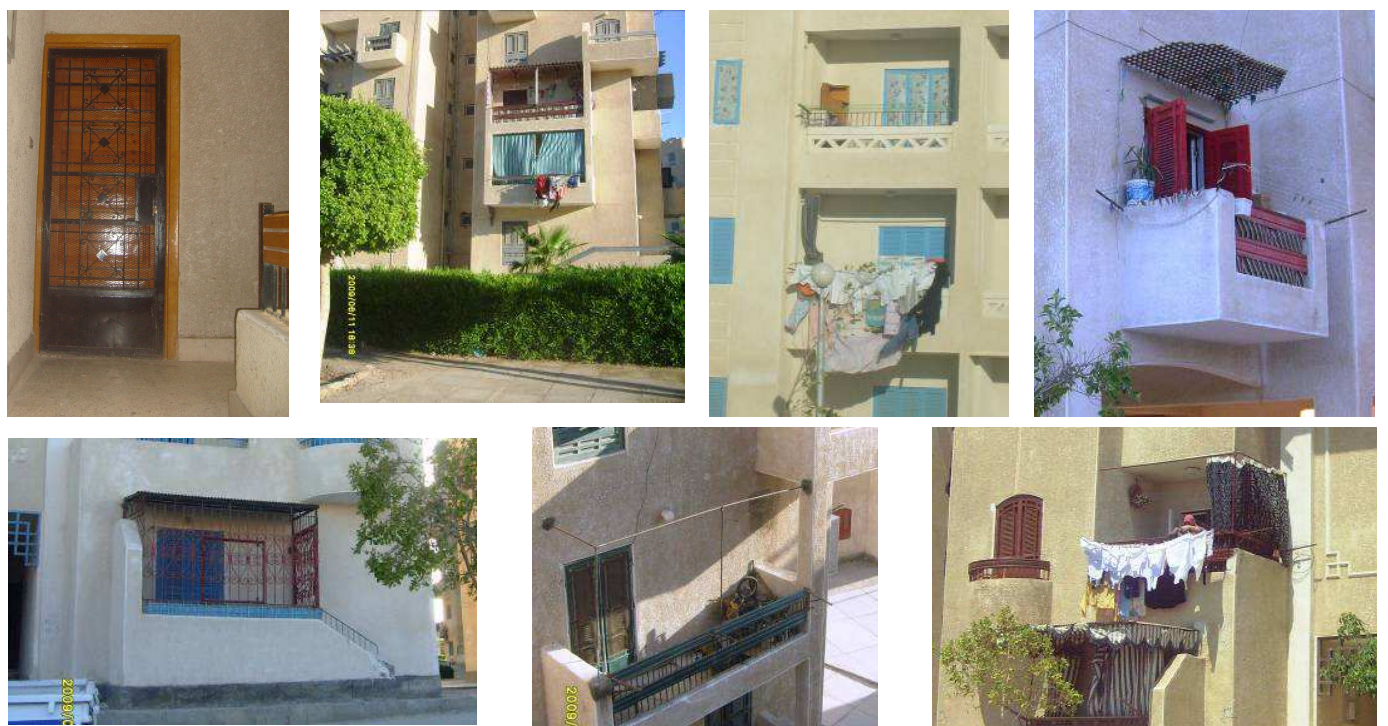

شكل (8) : تعديلات المستعمل علي

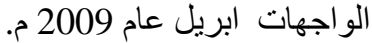
"المصدر الباحث: أبريت
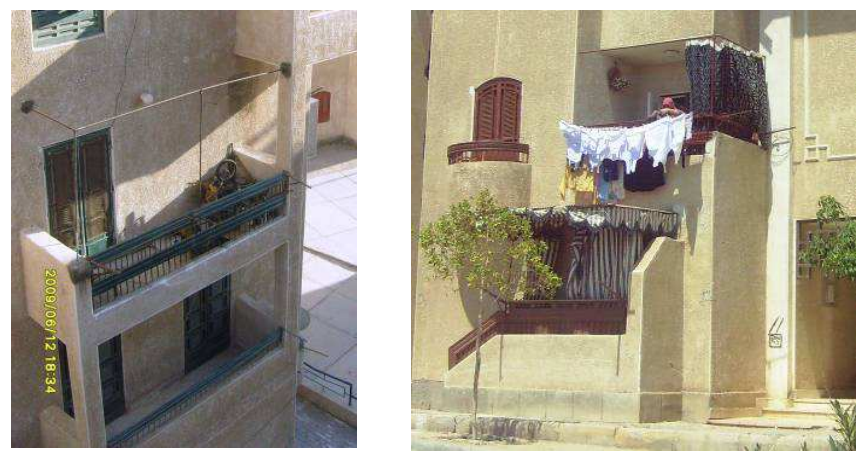

5-3-2 مناقشة تحليل استبيان المعمارى فى مدينة أسيوط الجليدة :

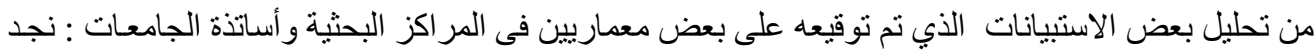

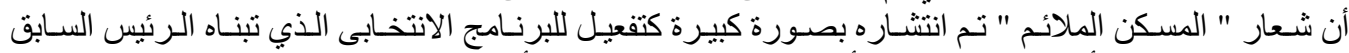

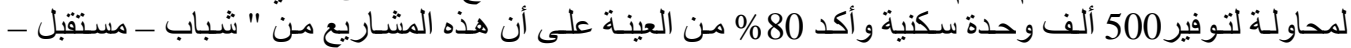

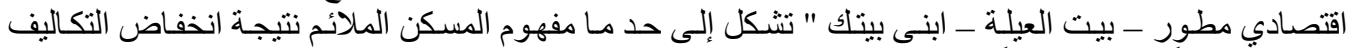

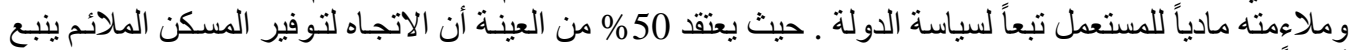

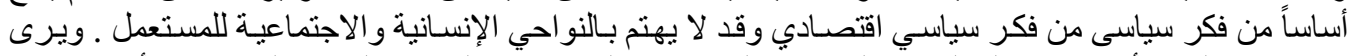

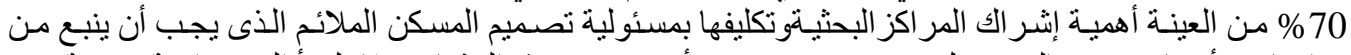

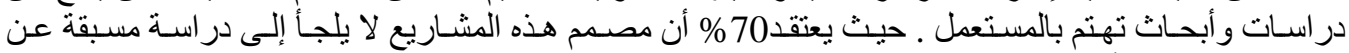

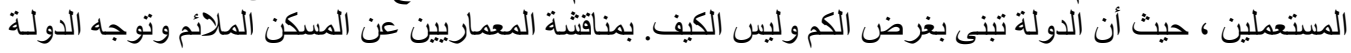

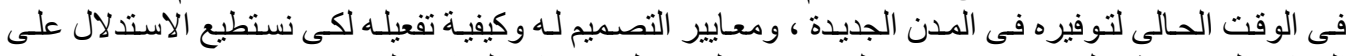

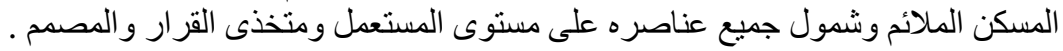

6-3-2 عرض بعض الآراء التى تم تسجيلها عن طريق الأسئلة المفتوحة فى الاستبياتات :

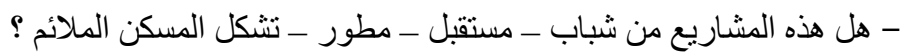

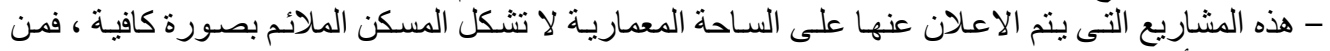

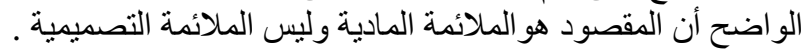

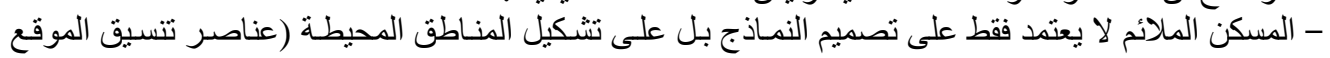

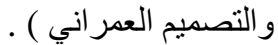
- هذه المشاريع لاتلبى احتباجات السكان من الثباب المستقبلية علي الاطلاق. 
- مساحة هذه النماذج تتر اوح بين ( 40-50-57-63 ) متر 2 و هـى لا يمكن معها توفير فر اغات مناسبة للحياة

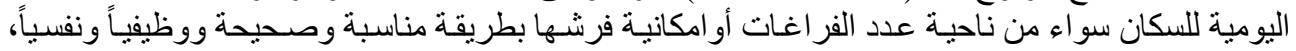

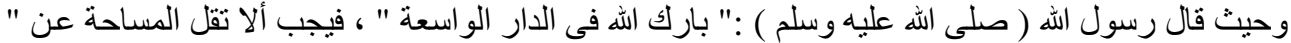

80 متر مربع، وان هذه النماذج تثكل المسكن الملائم ولكن فى المرحلة الأولى للأسرة ( أسرة ناشئئة ) .

جدول (2) :مقارنة بين بعض نتائج استبيان المستعمل ونتائج بعض المعماريين :

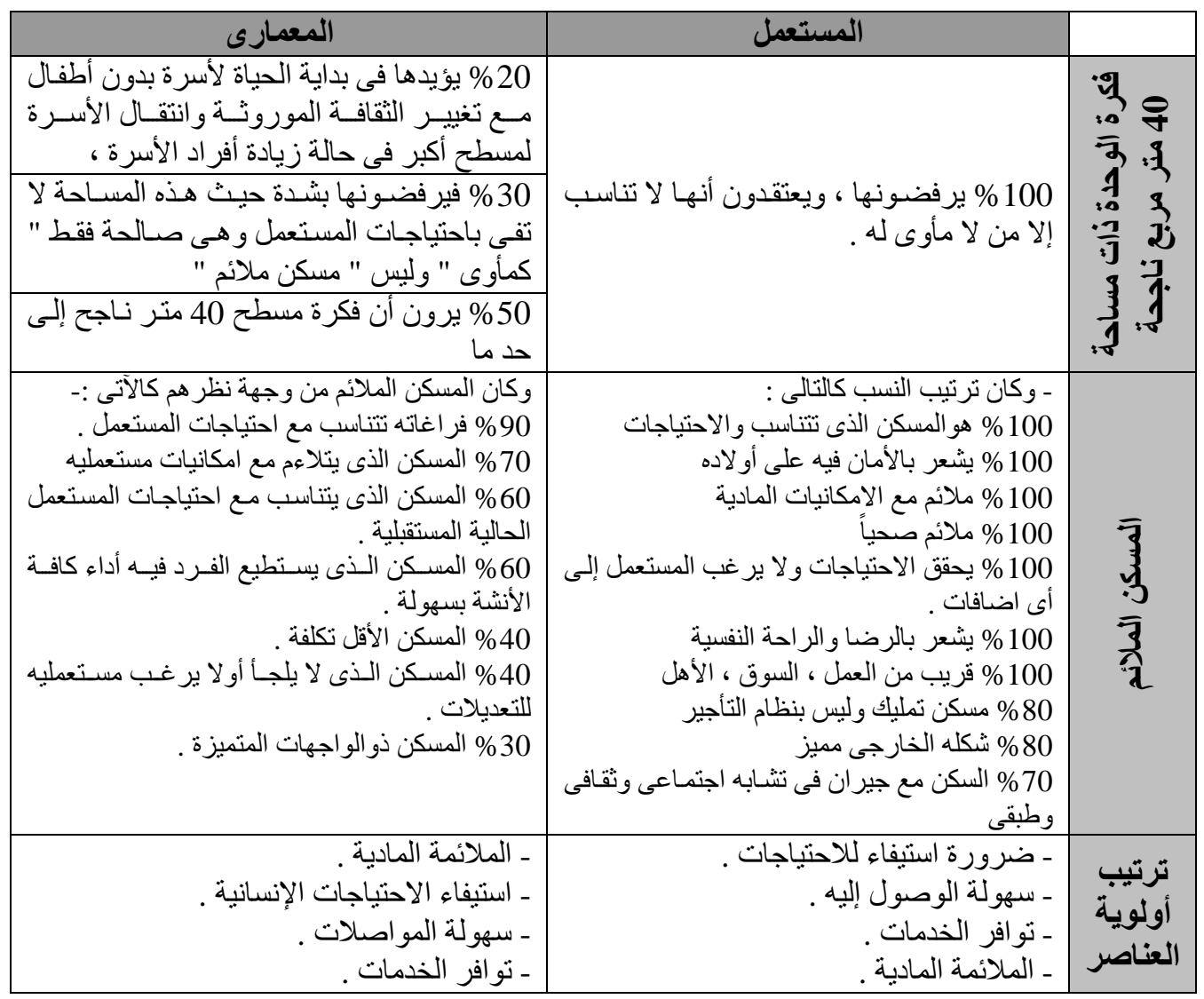

3- نتائسج تحليل اسـتبيان المستعل:

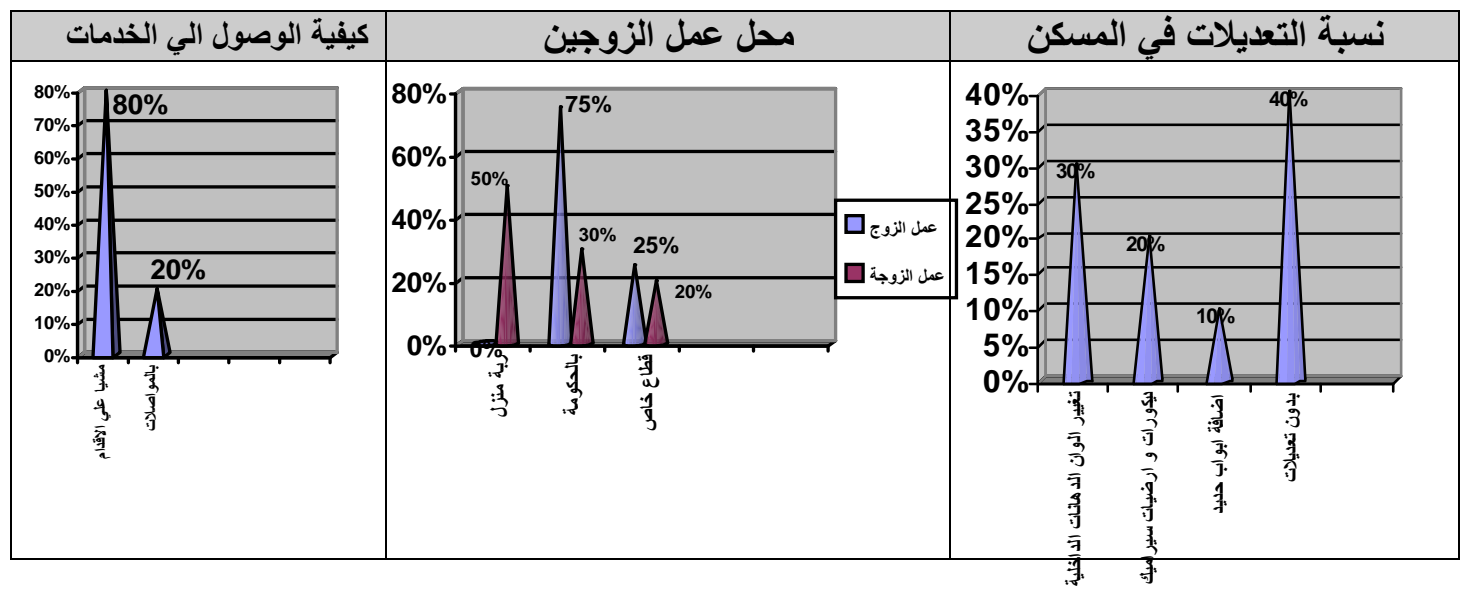




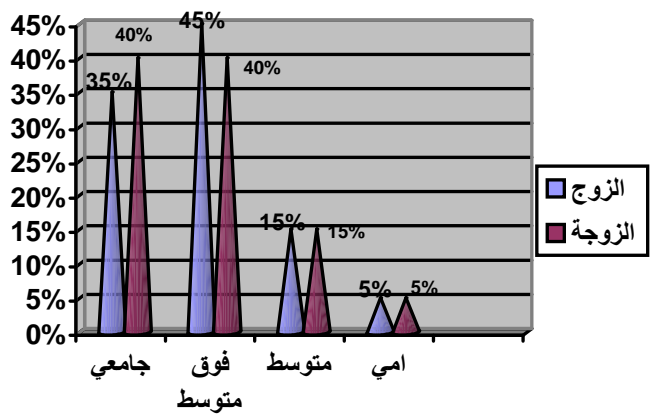

مستــوي التعليم

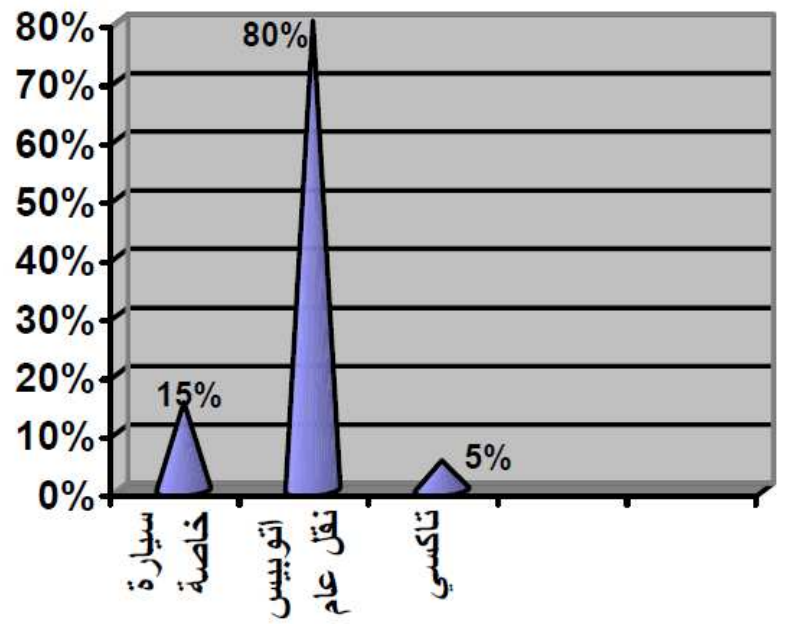

وسيلة الانتقال للعمل

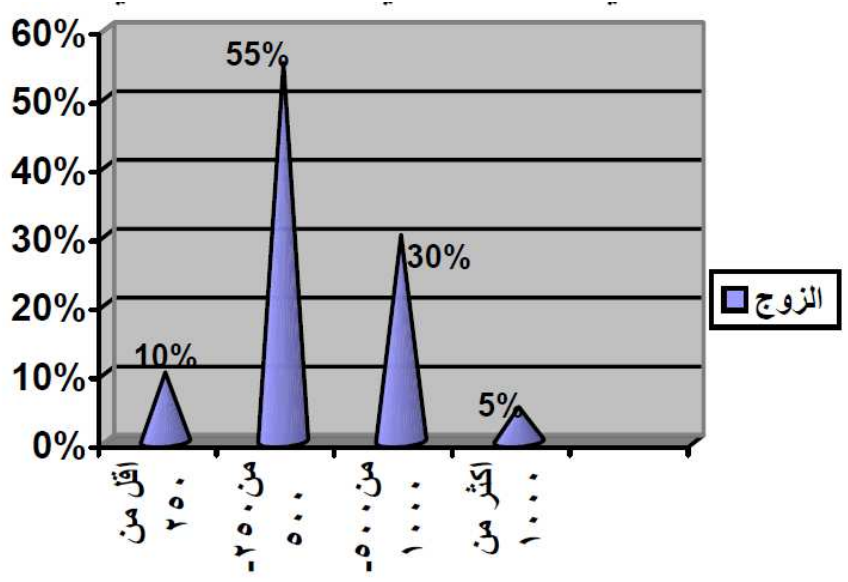

مستـــوي الدخل الشهري- بالجنيه المصري 
تابع نتائهـج الاسـتبيان : "الهصدر : الباحث"

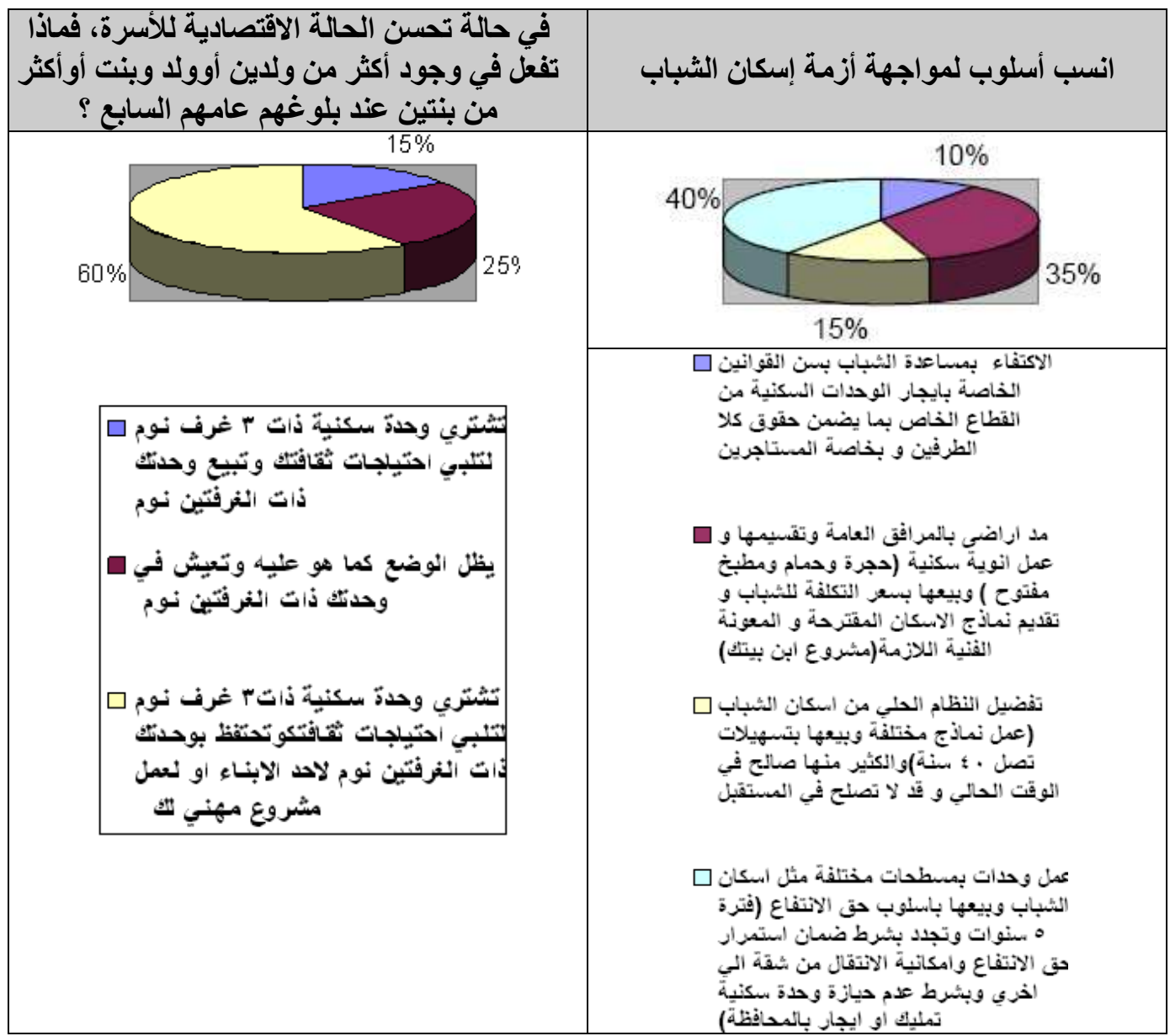

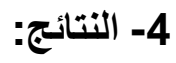

استخلاصـاً مـن الدر اسـة النظريـة والدر اسـات الميدانيـة للنو احي الاقتصـادية (الاحتياجـات و الإمكانيـات المتاحـة

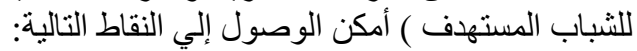
• من تحليل بيانات استعمال للمستعملين بالمنطقة والفية ورجد أن النسبة العظمي منهم متعلمين ومن الثباب ومتوسط

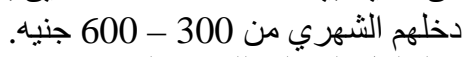
ـ ـ الحلول الداخلية للوحدة السكنية تعكس الاحتياجات الأساسية للساكن وتختلف التشطيبات الداخلية من أسرة

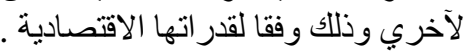

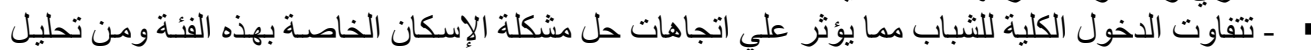

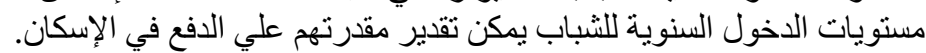

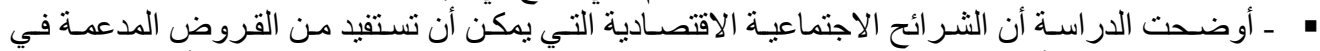

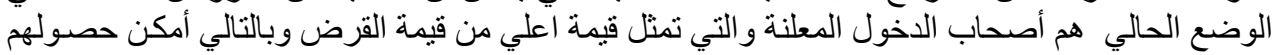

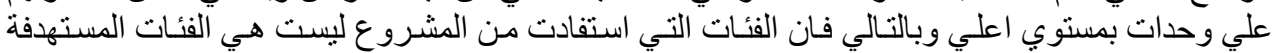
وبالتالي معظم الوحدات السكنية بالمشروع وجيال فان الفي إلي غير مستحقيها. 


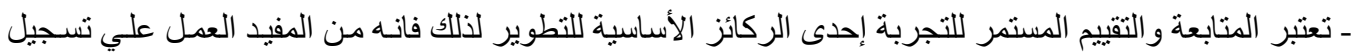

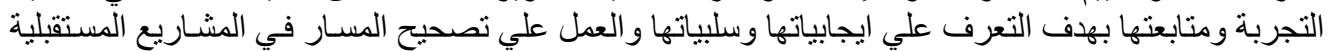

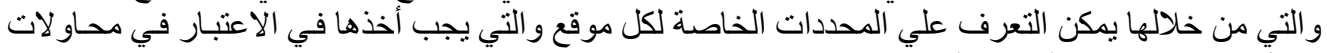
تعديل وتطوير مفهوم النماذج السكنية .

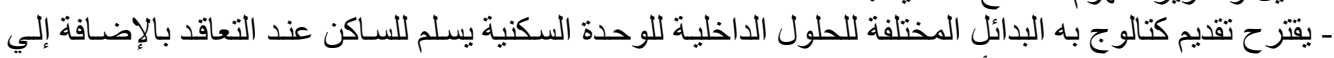

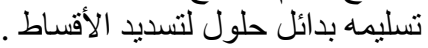

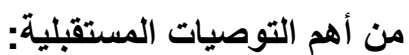

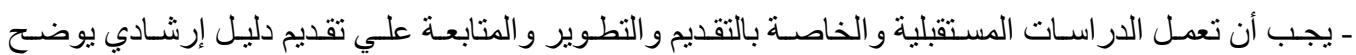

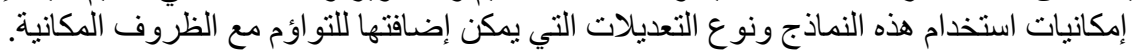

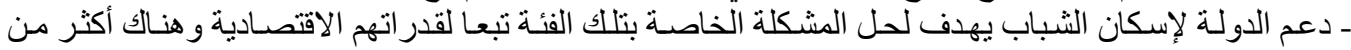

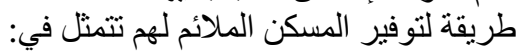

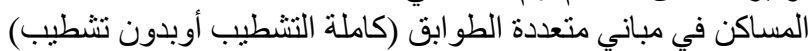

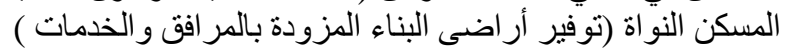

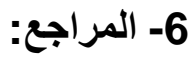

1- برنـامج الأمم المتحدة الإنمائي - 2006 ـ تقرير التنميـة البشرية لمصر 2005 ـ تلبيـة احتياجـات الفقراء من الوحدات السكنية ـ القاهرة.

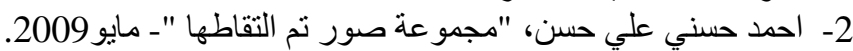

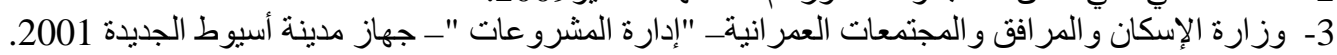

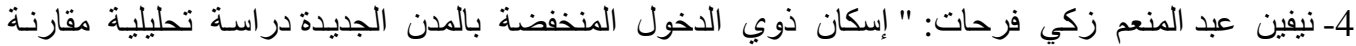

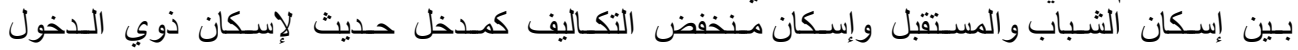

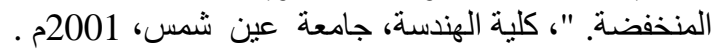
5- الجهاز المركزي للتعبئة العامة و الإحصاء.

6- http://www.urban-comm.gov.eg/1.as =

7- Ashraf Mansour Habib Mansour : "low cost housing in limited resources countries", Engineering Faculty, Cairo University 1994.

8 - Farid Motaz : "the Economics of the youth housing program ", Engineering Faculty, Cairo University 1998 .

9 -http:// www.urban-comm.gov.eg

10 -http:// www.hbrc.edu.eg

11 -http:// www.cpas-egypt.com 